accepted in this country as being on a par with the BDS qualification (as are dental qualifications from most non-EU countries), and the courtesy title $\mathrm{Dr}$ is granted with these EU qualifications, as is the BDS at present.

It could be argued very strongly that the GDC is in breach of EU law if they withdraw the courtesy 'Dr' title from English/British dentists.

EU dentists would still be entitled to be called 'Dr' even if British dentists were not allowed. This would be seen as 'active professional discrimination' against British dentists, and it could also be argued that it would also be a breach of UK dentists' rights.

We should also remember that our medical colleagues' 'Dr' title is also a courtesy title. The title 'Dr' can really only be used be those who achieve a 'Doctorate' title, ie PhD.

The GDC are not above the law and should be reminded as such!

Well I guess that's qualified me for a place in the 'Grumpy Old Men' team; move over Rick Wakeman. Now what other issue can I find to rant on about?

R. Piper

By email

DOI: 10.1038/sj.bdj.2010.826

\section{COURTESY TITLES}

Sir, the problem of the title 'Doctor' could be solved very easily, if only those who have a PhD or MD were allowed to use that title. Most patients are unaware that their general medical practitioner's title 'doctor' is also a courtesy title. For example in the medical practice of which I am a patient we have only one genuine 'Doctor' and she qualified in France; the rest are MB, ChB and the like with their various diplomas.

S. Zangwill, By email

DOI: 10.1038/sj.bdj.2010.830

\section{A DELIGHTFUL PROCLAMATION}

Sir, I have long admired the boy who called out from amongst the crowd, 'The Emperor hasn't got any clothes on!'

This and similar radical statements are a delightful proclamation of the truth.

Thank you for saying exactly what I and many others have been thinking: the GDC are not protecting patients from the inequities of this present dental contract (BDJ 2010; 209: 103).
I am grateful that you have shown that Dentist 50533 and most other numbers are still trying to protect patients, despite the toothlessness of the Council.

Let us all stay worthy of trust.

T. Rhodes

Westbury

DOI: 10.1038/sj.bdj.2010.827

\section{THE DEFINITIVE PAPER}

Sir, I was delighted to see the technique of coronectomy being advocated for the treatment of lower third molars where there is the possibility of damage to the inferior alveolar nerve (BDJ 2010; 209: 111-114). I am quoted in the article but the reference given is to an abstract of a paper I gave at the annual meeting of the British Association of Oral and Maxillofacial Surgeons. The reference for the definitive paper is: O'Riordan B C. Coronectomy (Intentional Partial Odontectomy of lower third molars). Oral Surg Oral Med Oral Path Oral Radiol Endod 2004; 98: 274-280. This is a retrospective study of coronectomy over a ten-year period with followup of four cases over ten years, 15 patients over 5-9 years and 33 patients over 2-4 years. Any interested reader going to the abstract will be disappointed to find that is just that, but will find the illustration of radiographs, method, results and discussion in the definitive paper.

B. C. O'Riordan

Watford

DOI: 10.1038/sj.bdj.2010.828

\section{HYPOCRITICAL TOSH}

Sir, I write with some disappointment regarding the letter Diagnosis tosh (BDJ 2010; 209: 106).

Having been fully committed to NHS dentistry for over 35 years I assume that the author did not offer the endodontic treatment to be carried out under NHS services. I also assume that the two young ladies concerned were charged considerably more than the $£ 45.60$ that would be payable for NHS treatment for the molar endodontic treatment and associated restoration as those practitioners committed to the NHS have to. Something's wrong somewhere.

Hypocritical tosh!

R. Moore

Birmingham

DOI: 10.1038/sj.bdj.2010.829 